khi người bệnh vừa trải qua một giấc ngủ dài, các cơ quan vân động chưa được thực hiện linh hoạt do vậy dễ khiến cho người bệnh vận động khó khăn hơn và mất thăng bằng hơn do vậy dề bị ngã hơn. Thời điểm ban tối, cũng là một yếu tố thuận lợi khiến cho người bệnh cao tuổi dể bị ngã, ở người cao tuổi do có sự suy giảm về thị lực vậy khi trời tối, người bệnh có thể sẽ khó khăn khi nhìn đường hay các chướng ngại vật trong quá trình di chuyển do vậy thời điểm ban tối cũng là thời điểm người bệnh rất dễ bị ngã.

Hậu quả của ngã ở người cao tuổi thường nghiêm trọng hơn nhiều so với người trẻ. Nghiên cứu của chúng tôi cho thây tỷ lệ đối tượng nghiên cứu có biến chứng gãy xương khi ngã là $87,5 \%$. Kết quả nghiên cứu này của chúng tôi cũng tương tự với một số các tác giả khác trên thế giới. Một nghiên cứu đánh giá có hệ thống về dịch tễ học về ngã và gãy xương do loãng xương của nhóm tác giả Alan Morrison và cộng sự (2013) cho thấy tỷ lệ gãy xương do loãng xương dao động từ $71,6 \%$ đến $92,4 \%$ ở tất cả các vị trí loãng xương trong dân số nghiên cứu chung. Trong đó tỷ lệ gãy xương do loãng xương ở nữ là 80 - 92,4\% còn ở nam giới là 71,6 $78,6 \%$ [8].

\section{KẾT LUÂ̂N}

Biến chứng gãy xương sau ngã chiếm tỷ lệ rất cao trên bệnh nhân cao tuổi có loãng xương. Cần tăng cường các biện pháp dự phòng ngã để giảm tỷ lệ ngã ở nhóm đối tượng này, góp phần giảm thiểu hậu quả do ngã trên người cao tuổi cũng như gánh nặng xã hội.

\section{TÀI LIÊU THAM KHẢO}

1. Fu D., Kalache A., Yoshida S.(2007), "WHO global report on falls prevention in older age". France: World Health Organization," France: World Health Organization.

2. Lúcia C.P, Raimunda B.D.S., Sirlei S.M., et al (2010), "Predictors of Falls in Women With and Without Osteoporosis", Journal of Orthopaedic \& Sports Physical Therapy, 40(9), tr. 582-588.

3. Wim V, Lankveld E.S., Roland L., et al (2011), "Does osteoporosis predispose falls? a study on obstacle avoidance and balance confidence", BMC Musculoskeletal Disorders 12.

4. Paek K.W., Cho J.P., Song H.J., et al (2001), "Prevalence and associated factors of falls in the elderly community", Korean J Prev Med, 34, tr. 47-54.

5. Cooper C., Gale C.R., Aihie S. (2016), "Prevalence and risk factors for falls in older men and women: The English Longitudinal Study of Ageing", Age Ageing, 46(6), tr. 789-794.

6. Meng-Meng H., Hong-Ying $P_{\text {., }}$ Jie Z Zh., et al (2015), "Circumstances of falls and fall-related injuries among frail elderly under home care in China," International Journal of Nursing Sciences ," 2(3), tr. 237-242.

7. Morgan K., Blake A.J., Bendall M.J., (1988), "Falls by elderly people at home: prevalence and associated factors", Age Ageing, 17(6), tr. 365-72.

8. Fan T., Morrison A., Sen S.S., Weisenfluh L. (2013), " Epidemiology of falls and osteoporotic fractures: a systematic review", Clinicoecon Outcomes Res, 5, tr. 9-18.

\title{
KẾT QUẢ ĐÎ̀̂U TRI THOÁI HÓA KHỚP GỐI NGUYÊN PHÁT BẰNG LIÊUU PHÁP TIÊM NộI KHỚP ACID HYALURONIC KẾT HỢP SORBITOL
}

\section{TÓM TẮT.}

Mục tiêu: Đánh giá kết quả và tác dung không mong muốn của liệu pháp tiêm nội khớp acid hyaluronic kết hợp sorbitoltrong điều trị thoái hóa khớp gối nguyên phát. Đối tượng và phương pháp: Nghiên cứu tiến cứu, can thiệp, có nhóm chứng, theo dỗi dọc trên 101 bệnh nhân với 151 khớp gối thoái hóa giai đoạn II, IIİ theo Kellgren và Lawrence, chia làm 2 nhóm: nhóm can thiệp được tiêm 1 ống Synolis

\footnotetext{
${ }^{1}$ Bệnh viện hữu nghị đa khoa Nghệ An, ${ }^{2}$ Trường Đại học Y Hà Nội Chịu trách nhiệm chính: Phạm Hoài Thu Email: phamhoaithu@hmu.edu.vn Ngày nhận bài: 12.7.2021 Ngày phản biện khoa học: 6.9.2021 Ngày duyệt bài: 13.9.2021
}

Nguyễn Thị Lý1, Nguyễn Thị Ngọc Lan², Phạm Hoài Thu ${ }^{2}$

VA 80/160mg vào khớp gối tổn thương, nhóm chứng được điêu trị bằng thuốc đường uống Mobic, Viatril $S$. Kết quả điều trị: Điểm VAS, WOMAC, biên độ gấp gối ở nhóm can thiệp có sự cải thiện rõ rệt bắt đâu từ tuân thứ 4 và tiếp tực cho đến tuần 12 , tốt hơn nhóm chứng có ý nghĩa thống kê $(\mathrm{p}<0,01)$. Sau 12 tuần điều trị,, điểm VAS giảm từ 5,28 xuống 1,24, tỷ lệ đau vữa/nặng giảm từ $100 \%$ xuống $6,8 \%$,có $39,2 \%$ không đau, điểm WOMAC chung giảm từ 36,46 xuống 12,27 , biên độ gấp khớp gối tăng them 19,46 $\pm 11,84$ độ, tỷ lệ hài lòng và rất hài lòng $92,3 \%(p<0,01)$. Không gắp tác dụng không mong muốn nghiêm trọng, 28,4\% cằng tức khớp gối sau tiêm,12,2\% đau sau tiêm trong vòng 12-24 giớ, $4,1 \%$ tràn dịch khớp. Kết luận: Liệu pháp tiêm nội khớp acid hyaluronic kết hợp sorbitolcó tác dụng giảm đau nhanh, cải thiện chức năng vận động của khớp gối tốt hơn nhóm chứng và có tính an toàn.

Tư khóa: Thoái hóa khớp gối nguyên phát, Synolis VA, acid hyaluronic, sorbitol. 


\section{SUMMARY \\ THE TREATMENTRESULTS OF PRIMARY KNEE OSTEOARTHRITIS BY HYALURONIC ACID COMBINED WITH SORBITOL}

Objectives: Evaluate the results and the safe of intra-articular injection by hyaluronic acid combined with sorbitolto treat primary knee osteoarthritis. Subjects and methods: Prospective, interventional, vertical following-up study with a control group, 101 patients with 151 osteoarthritis knees in grade II, III according to Kellgren and Lawrence, divided into two groups: the intervention group was intra-articular injected a single Synolis VA $80 / 160 \mathrm{mg}$ into knee osteothritis, the control group was treated with oral medicine Mobic, Viatril S. Result: VAS pain score, WOMAC index, and knee range of motion of intervention group have significantly improved starting from the 4-week and continuing until the 12-week, statistically better than the control group $(p<0,01)$. After 12 weeks, VAS score decreased from 5,28 to 1,24 , The proportion of moderate and severe pain decreased from $100 \%$ to $6,8 \%, 39,2 \%$ no pain. The total WOMAC score reduced from 36,46 to12,27 $(p<0,01)$. The amplitude of knee flexion increased by $19,46 \pm 11,84,(p<0,01)$. The rate of satisfaction and very satisfaction was $92,3 \%(p<0,01)$. There were no serious side effects, $28,4 \%$ knee tension after injection, $12,2 \%$ painafter injection $12-24$ hours, $4,1 \%$ effusions. Conclusion: Intra-articular injection therapy of hyaluronic acid combined with sorbitol has a fast painrelieving effect and improves motor function better than the control group and have quite safety.

Key words: Primary knee osteoarthritis, hyaluronic acid, sorbitol, Synolis VA.

\section{I. ĐẶT VẤN ĐỀ}

Thoái hóa khớp là bênh lý tổn thương của toàn bộ các thành phần của khớp, trong đó tổn thương chính ở sụn khớp. Theo tổ chức y tế thế giới, thoái hóa khớp chiếm 10-15\% dân số trên 60 tuổi gây tàn tât cho 10 triệu phụ nữ và 6,5 triêu nam giới mối năm ${ }^{1}$. Các biên pháp điều trị hiện nay còn nhiều hạn chế. Acid Hyaluronic (HA) là thành phần chính quyết định độ nhớt và tính đàn hồi của dịch khớp, chống viểm, giảm đau và bảo vệ sụn khớp. Theo các nghiên cứu, trong khớp thoái hóa có giảm đáng kể nồng độ và trọng lương phân tử của $\mathrm{HA}$ gây đau và hạn chế vận động. Ứng dụng điều trị HA cho bệnh nhân thoái hóa khớp gối hơn 40 năm, đã chứng minh hiệu quả giảm đau, cải thiện chức năng vận động khớp qua nhiều nghiên cứu ${ }^{2,3}$. Tuy nhiênHA dễ dàng bị phá hủy bởi các gốc tự do có trong các khớp thoái hóa. Sorbitol là một chất khử gốc tự do mạnh,kết hợp nồng độ cao $\mathrm{HA}$ $(20 \mathrm{mg} / \mathrm{ml}) 2 \mathrm{MDa}$ trong chẩt nhờn Synolis VA, tạo thành mạng lưới dày đặc các liên kết Hydro giúp ổn định phức hợp, nhẳm loại bỏ các gốc tự do để HA tồn tại lâu hơn trong khớp ${ }^{4,5}$. Một số tác giả trên thế giới đã tiến hành nghiên cứu và cho thấy hiệu quả tốt trong điều trị thoái hóa khớp gối 6,7 . Vì vậy chúng tôi nghiên cứu đề tài này nhằm2 mục tiêu:

1. Đánh giá kết quả điều trị của liệu pháp acid hyaluronic kêt hợp sorbitol trong điều trị thoái hóa khớp gối nguyên phát.

2. Nhận xét các tác dụng không mong muốn của liệu pháp này.

\section{II. ĐỐI TƯỢNG VÀ PHƯƠNG PHÁP NGHIÊN CỨU}

2.1 Đối tượng nghiên cứu. 101 bệnh nhân điều trị tại khoa Nội tổng hợp Bệnh Viện Đại học Y Hà Nội và khoa Cơ xương khớp Bênh Viển Bạch Mai từ tháng 10 năm 2020 đến tháng 7 nămm 2021, được chẩn đoán thoái hóa khớp gối nguyên phát theo tiêu chuẩn của Hội thấp khớp học Mỹ ACR 1991, giai đoạn II và III theo phân loại của Kellgren_Lawrence, VAS $\geq 4$ điểm, không có dịch hoặc tràn dịch mức độ ít $(<5 \mathrm{~mm})$ trên siêu âm khớp gối và chấp nhận tham gia nghiên cứu.

Loại khỏi nghiên cứu các bênh nhân cóchống chỉ định tiêm nội khớp gối (nhiểm khuẩn tại khớp và toàn thân, rối loạn đông và chảy máu, suy gan nặng, suy thận nặng, đái tháo đường chưa kiểm soát), thoái hóa khớp gối thứ phát (sau chấn thương, viêm khớp dạng thấp, gút...), hoặc đã tiêm corticosteroid trong 1 tháng, acid hyaluronic trong 6 tháng hoặc huyết tương giàu tiểu cầu hoặc tế bào gốc hoặc can thiệp ngoại khoa tại khớp gối. Ngừng thuốc chống viêm steroid trước nghiên cứu 7 ngày.

\subsection{Phương pháp nghiên cứu}

- Thiết kế nghiên cứu: Nghiên cứu tiến cứu, can thiệp, thẽo dõi dọc, có nhóm chứng

- Chọn mẫu và cỡ mấu: chọn mấu thuận tiện, 101 bệnh nhân đủ tiêu chuẩn, chia thành 2 nhóm:

+ Nhóm can thiệp: 52 bệnh nhân (74 khớp), mỗi khớp được tiêm 1 mũi Synolis VA $80 \mathrm{mg} /$ $160 \mathrm{mg}$, uống Mobic 7,5 mg $1-2$ viên/ngày khi đau, tối đa 15 ngày/đợt, Viatril-S $1500 \mathrm{mg} /$ ngàyduy trì 3 tháng.

+ Nhóm chứng: 49 bệnh nhân (77 khớp) điều trị Mobic7,5mg 1 - 2 viên/ngày khi đau,tối đa 15 ngày/ đợt, Viatril-S $1500 \mathrm{mg} /$ ngàyduy trì 3 tháng.

- Đánh giá kết quả điều trị theo thang điểm đau VAS, tỷ lệ phân bố các mức độ đau VAS,chì số WOMAC, số đo góc gấp khớp gối tai các thời điểmT0 (trước điều tri), T1, T4, T8 và T12 (sau điều trị $1,4,8$ và 12 tuần), mức độ hài lòngsau 12 tuần. Các tác dụng không mong muốn được ghi nhận và xử trí ở bất kỳ thời điểm nào trong 12 tuần theo dõi. 
2.3 Xử lí số liệu: Phần mềm thống kê SPSS 20.0, sử dụng sự khác biệt có ý nghĩa thống kê khi $\mathrm{p}<0,05$.

III. KẾT QUẢ NGHIÊN CỨU

3.1 Đặc điểm chung của nhóm bệnh nhân nghiên cứu

Bảng 1: Đặc điểm chung của đối tượng nghiên cứu

\begin{tabular}{|c|c|c|c|c|c|}
\hline \multirow{2}{*}{\multicolumn{2}{|c|}{ Đặc điểm }} & Nhóm can thiệp & Nhóm chứng & Tổng & \\
\hline & & $n=52 \mathrm{BN}$ & $n=49 \mathrm{BN}$ & $n=101 B N$ & $\mathbf{p}$ \\
\hline \multicolumn{2}{|c|}{ Tuổi (năm) } & $62,98 \pm 10,84$ & $62,35 \pm 9,77$ & $62,67 \pm 10,29$ & $>0,05$ \\
\hline \multicolumn{2}{|c|}{ Giới } & Nữ $90,4 \%$ & Nữ 79,6\% & Nữ $85,1 \%$ & $>0,05$ \\
\hline \multicolumn{2}{|c|}{ BMI $\left(\mathrm{kg} / \mathrm{m}^{2}\right)$} & $23,22 \pm 2,41$ & $23,61 \pm 2,56$ & $23,41 \pm 2,48$ & $>0,05$ \\
\hline \multirow{2}{*}{$\begin{array}{c}\text { Nghề } \\
\text { nghiệp }\end{array}$} & Trí óc & $22(42,3 \%)$ & $15(30,6 \%)$ & $37(36,6 \%)$ & \multirow{2}{*}{$>0,05$} \\
\hline & Chân tay & $30(57,7 \%)$ & $34(69,4 \%)$ & $63(63,4 \%)$ & \\
\hline \multirow{2}{*}{ Giai đoạn } & II & 52khớp (70,3\%) & 55khớp(71,4\%) & 107khớp (70,9\%) & \multirow{2}{*}{$>0,05$} \\
\hline & $\frac{\text { III }}{\text { bênh (năm) }}$ & $\frac{22 \text { khớp }(29,7 \%)}{5,30 \pm 5,01}$ & $\frac{22 \mathrm{khớ} p(28,6 \%)}{6,31 \pm 5,80}$ & $\frac{44 \text { khớp }(29,1 \%)}{581 \pm 5,43}$ & \\
\hline
\end{tabular}

Nhân xét: Khồng có sự khác biêt về các chỉ số nhân trắc, nghề nghiệp, thời gian mắc bênh và giai đoạn bệnh trước điều trị giữa 2 nhóm nghiên cứu với $p>0,05$.

3.4 Kết quả điêu trị thoái hóa khớp gối bằng acid hyaluronic kết hợp sorbitol 3.4.1 Kết quả điều trị theo điểm VAS

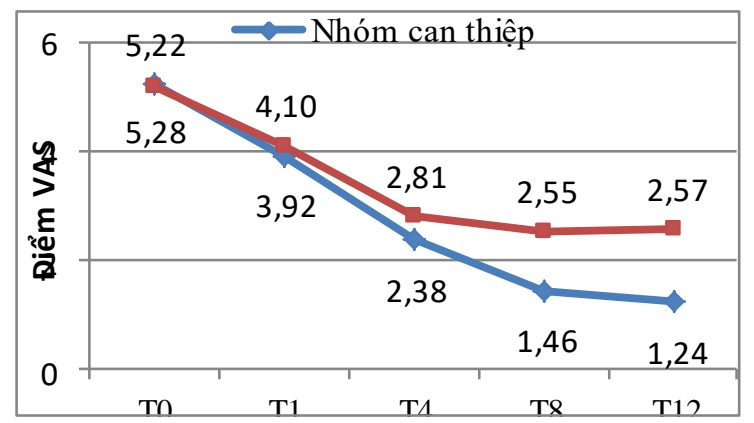

Biểu đồ 1: Thay đổi điểm VAS của 2 nhóm tại các thời điểm nghiên cứu

Nhận xét: Điểmđau VAS trung bình của 2 nhómgiảm dần từ thời điểm T0 đến T12.Tại các thời điểm T4, T8 và T12, điểm VAS của nhóm can thiệpcó sự cải thiên rõ rệt hơn nhóm chứng, có ý nghĩa thổng kê với $p<0,05$.

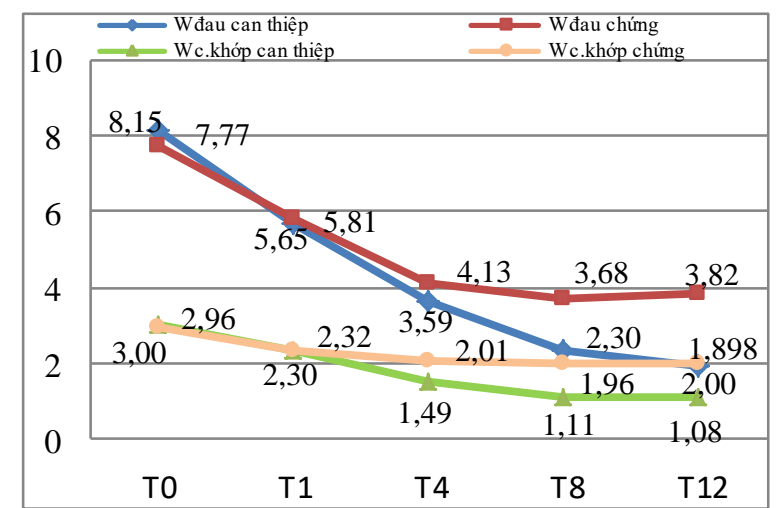

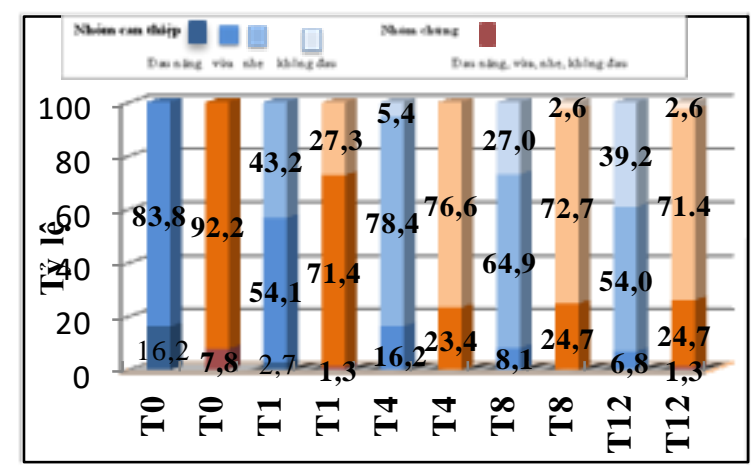

Biểu đồ 2: Mức độ đau VAS của 2 nhóm nghiên cứu tại các thời điểm

Nhân xét: Sự phân bố mức độ đau giữa 2 nhóm trước và sau điều trị 1 tuần khác biệt không có ý nghĩa thống kê(p>0,05).Tại các thời điểm T4, $T 8$ và $T 12$, tỷ lệ đau nặng/ vừa giảm dần, đau nhẹ/ không đau tăng. Nhóm can thiệp có sự cải thiện rõ rệt hơn nhóm chứng với $p<0,05$.

3.4.2 Kêt quả điều trị theo điểm WOMAC

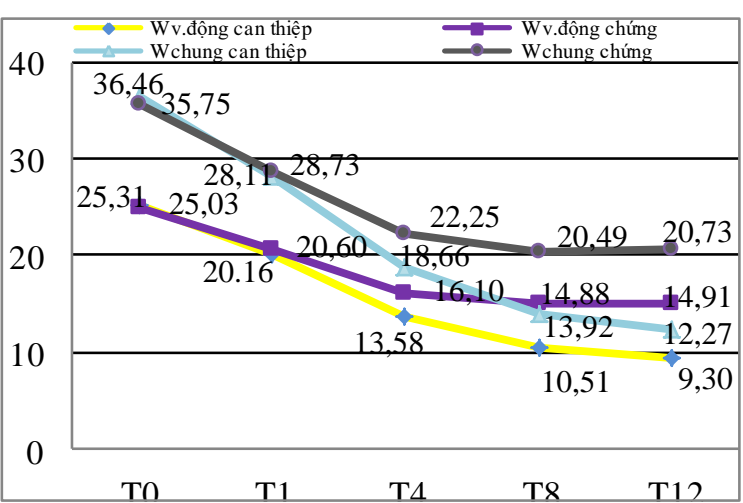

Biểu đồ 3: Chỉ số WOMAC đau, cứng khớp, vận động và chung của 2 nhóm 
Nhân xét: Điểm WOMAC chung, đau, cứng khớp và vận động không có sự khác biệt giữa 2 nhóm $(p>0,05)$ tại thời điểm bắt đầu điều trị và sau 1 tuần điều trị $(T 0, T 1)$. Sau điều trị 4,8 và 12 tuần, điểm WOMAC đau, cứng khớp, vận động và chung của nhóm can thiệp thấp hơn nhóm chứng có ý nghĩa thống kê với $p<0,05$.

3.4.3 Kêt quả điều trị theo góc vận động và thời gian phá rỉ khớp

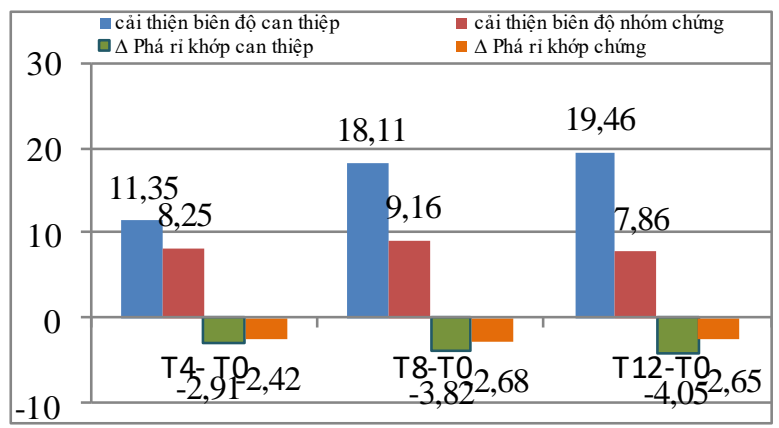

Biểu đồ 4: Cải thiện biên độ vận động và thời gian phá rỉ khớpcủa 2 nhóm

Nhận xét: Sau 4 tuần điều trị, biên độ vận động gấp gối và thời gian phá rỉ khớp có sự cải thiện và tiếp tục cải thiện sau 8 tuần và 12 tuần điều trị ở cả 2 nhóm, trong đó nhóm can thiệp có sự cải thiện nhiều hơn nhóm chứng, sự khác biệt có ý nghĩ̃a thống kê với $p<0,05$.

\subsubsection{Mức độ hài lòng sau 3 tháng \\ Bảng 2: Mức độ hài lòng của người bệnh sau 12 tuần điều trị}

\begin{tabular}{|c|c|c|c|}
\hline Mức độ & $\begin{array}{c}\text { Nhóm can } \\
\text { thiệp } \\
(\mathrm{n}=52 \mathrm{BN})\end{array}$ & $\begin{array}{c}\text { Nhóm } \\
\text { chứng }(\mathrm{n}= \\
\text { 49BN) }\end{array}$ & $\mathbf{p}$ \\
\hline $\begin{array}{l}\text { Không hài } \\
\text { lòng }\end{array}$ & $4(7,7 \%)$ & $21(42,9 \%)$ & \multirow{4}{*}{$\underset{0,01}{<}$} \\
\hline Hài lòng & $28(53,1 \%)$ & $26(53,1 \%)$ & \\
\hline Rất hài lòng & $20(38,5 \%)$ & $2(4,1 \%)$ & \\
\hline $\begin{array}{l}\text { Điếm Likert } \\
\text { trung bình }\end{array}$ & $6,92 \pm 1,49$ & $4,82 \pm 1,50$ & \\
\hline
\end{tabular}

Nhận xét: Sau 3 tháng điêu trị, tỷ lệ bệnh nhân hài lòng và rất hài lòng của nhóm tiêm can thiệp cao hơn nhóm chứng có ý nghĩa thống kê với $p<0,01$.

3.5 Tác dụng không mong muốn của tiêm Synolis VA

Bảng 3: Tác dụng không mong muốn của Synolis ( $n=74$ khớp)

\begin{tabular}{|c|c|c|}
\hline Đặc điếm & Số lượng & Tỷ lệ (\%) \\
\hline $\begin{array}{c}\text { Đauu sau tiêm } \\
\text { (kéo dài 12- 24 giờ) }\end{array}$ & 8 & 10,8 \\
\hline Căng tức sau tiêm & 20 & 27,1 \\
\hline Tràn dịch khớp & 3 & 4,1 \\
\hline Nhiêm khuấn khớp & 0 & 0,0 \\
\hline
\end{tabular}

\begin{tabular}{|c|l|l|}
\hline Đau đầu, chóng mặt & 0 & 0,0 \\
\hline Phản vệ & 0 & 0,0 \\
\hline
\end{tabular}

\section{BÀN LUẬN}

Trong điều trị thoái hoá khớp gối, acid hyaluronic có tác dụng bôi trơn, đàn hồi, giảm ma sát và kích thích sự tăng sinh tế bào sụn khớp và chất nền sụn khớp thông qua thụ thể CD44, chống viêm, giảm đau ${ }^{8}$. Do đó liệu pháp tiêm acid hyaluronic được chứng minh có tác dụng giảm đau, chống viêm, phục hồi sụn khớp và cải thiện vận động khớp gối. Trong nghiên cứu của chúng tôi cho thấy điểm VAS có sự cải thiện rõ rệt tại các thời điểm và tác dụng giảm đau của Synolis VA khá sớm. Điểm VAS trung bình của 2 nhóm tại thời điểm T0 là $5,25 \pm 1,00$, không có sự khác biệt $(p>0,05)$. Ngay sau 1 tuần điều trị, điểm VAS nhóm can thiệp đã giảm đáng kể từ $5,28 \pm 1,08$ xuống $3,92 \pm 1,21$ có ý nghĩa thống kê $(p<0,05)$. Tuy nhiên sự cải thiện này chưa rõ rệt và tương tự với nhóm chứng. Sau 4,8 và 12 tuần điều trị, điểm VAS tiếp tục giảm lần lượt $2,38 \pm 1,29 ; 1,46 \pm 1,27$ và $1,24 \pm$ 1,30 , thấp hơn nhóm chứng có ý nghĩa thống kê với $p<0,05$ (biểu đồ 1 ).

Tỷ lệ phân bố các mức độ đau cũng sự thay đổi nhiểu. Trước điều trị, 100\% bệnh nhân đau nặng và vừa, nhóm can thiệp có tỉ lệ đau nặng $16,2 \%$ cao hơn nhóm chứng $7,8 \%(P>0,05)$. Từ thời điểm $T 1$ đến $T 12$, tỷ lệ bệnh nhân đau nặng/ vừa giảm dần và đau nhẹ/ không đau tăng lên. Sau 12 tuần điều trị̂̉ nhóm can thiệp chỉ có $6,8 \%$ đau vừa, không có khớp nào đau nặng, $39,2 \%$ không đau, cải thiện tốt hơn nhóm chứng có ý nghĩa thống kê với $p<0,01$ (biểu đồ 2). Năm 2013]. Heisel và C.Kipshoven nghiên cứu trên 1147 bệnh nhân thoái hóa khớp gối giai đoạnI-IV được tiêm 3 mũi acid hyaluronic kết hợp với sorbitol (GO-ON matrix). Kết quả sau 6 tháng có $56,5 \%$ giảm mức độ đau từ $(2,61 \pm$ $0,80)$ đến $(1,07 \pm 0,86)$. Tỉ lệ bệnh nhân đau nặng/ rất nặng từ $56,2 \%$ xuổng $5,9 \%$, không đau / đau nhe tăng từ $6,8 \%$ lên $67,1 \% 6$.

Thang điểm WOMAC (Western Ontario and McMaster Universities Arthritis index) được sử dụng để đánh giá về hiệu quả điều trị giảm đau, cứng khớp và cải thiện vận động. Điểm càng cao thì chứng tỏ khớp gối càng tổn thương nặng. Trong nghiên cứu của chúng tôi, điểm WOMAC đau, cứng khớp, vận động và chung đều giảm dần sau tuần đầu điều trị cho đến tuần thứ 12. Ở nhóm can thiệp cho thấy sự cải thiện thang điểm WOMAC rõ rệt bắt đầu từ tuần thứ $4 \mathrm{sau}$ điều trị, tiếp tục cho đến tuần thứ 12 , thấp hơn 
nhóm chứng có ý nghĩa thống kê với $\mathrm{p}<0,01$ (riêng $T 4, p<0,05$ ). Cụ thể sau 12 tuần điều trị, WOMAC đau giảm từ $8,15 \pm 2,00$ xuống $1,89 \pm 1,80$, WOMAC cứng khớp giảm từ $3,00 \pm 1,68$ xuống $1,08 \pm 0,99$, WOMAC vận động giảm từ 25,31 $\pm 7,49$ xuống $9,30 \pm 6,03$, điểm

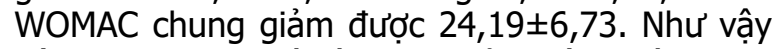
tiêm Synolis VA có tác dụng cải thiện chức năng vận động của khớp gối thoái hóa nhanh sau 4 tuần và kéo dài đến 12 tuần sau điều trị (biểu đồ 3). Tương tự kết quả của tác giả Phạm Thị Bích Ngọc (năm 2019) trên 76 bệnh nhân thoái hóa khớp gối giai đoạn II, III tiêm Regenflex Bioplus, điểm WOMAC chung giảm từ 38,68 xuống 11,6 điểm ${ }^{9}$. Năm2016, M. Bausani nghiên cứu trên 15 bệnh nhân thoái hóa khớp gối nặng giai đoạn III, IV được tiêm 3 mũi Synolis VÁ $2 \mathrm{ml}$. Sau 52 tuần điều trị, điểm WOMAC đau giảm từ 13,60 xuống 7,67, WOMAC cứng khớp giảm từ 6,3 xuống 3,20.

Tầm vận động của khớp gối cũng là một tiêu chí để đánh giá hiệu quả điều trị. Trong nghiên cứu của chúng tôi, tại thời điểm T0 số đo góc gấp khớp gối của nhóm can thiệp là 107,70 \pm 17,27 thấp hơn nhóm chứng $113,83 \pm 16,24$, sự khác biệt có ý nghĩa thống kê với $\mathrm{p}<0,05$. Biên độ gấp gối của nhóm can thiệp được cải thiện nhiều hơn nhóm chứng tại các thời điểm $\mathrm{T4}$, T8 và $T 12(p<0,01)$. Sau 12 tuần số đo góc gấp khớp gối tăng lên thêm $19,46( \pm 11,84)$ độ. Thời gian phá rỉ khớp cũng giám $-4,05( \pm 1,10)$ phút $(p<0,01)$ (biểu đồ 4).

Đánh giá mức độ hài lòng của bệnh nhân thông qua thang điểm Liker.Trong nghiền cứu sử dụng thang điểm Liker 10 điểm, chia thành 3 mức độ (0-4 điểm: không hài lòng, 5-7 điểm: hài lòng, 8-10 điểm: rất hài lòng). Sau 12 tuần điều trị, ở nhóm can thiệp có điểm Liker trung bình là $6,92 \pm 1,49$ cao hớn nhiều so với nhóm chứng $4,82 \pm 1,50(p<0,01)$, có $92,3 \%$ bệnh nhân hài lòng và rất hài lòng với liệu pháp điều trị, khác biệt nhóm chứng 59.2\% với p<0,01(bảng 2).

Tác dụng không mong muốn của Synolis VA ở 74 khớp gối được tiêm là 10,8\% đau sau tiêm (8 khớp) kéo dài 12 đến 24 giờ; $27,0 \%$ căng tức sau tiêm (20 khớp), chỉ xảy ra trong vòng 30 phút đến 1 giờ sau tiêm và tự hết sau khi bệnh nhân thực hiện động tác gấp duỗi khớp gối từ 10 đến 15 phút, khổng có bệnh nhân nào phải sử dụng thêm các phương pháp giảm đau khác, $4,1 \%$ tràn dịch (3 khớp). Nhìn chung đây là những tác dụng phụ không nghiêm trọng và không làm bệnh nhân bỏ theo dõi và điều trị.
Đặc biệt không có trường hợp nào nhiễm khuẩn khớp, tràn máu sau tiêm hay các tác dụng phụ nghiêm trọng (bảng 3). 2021 Cortet và cộng sự nghiên cứu đa trung tâm so sánh đối đầu giữa Synolis VA $80 / 160 \mathrm{mg}$ và Hylan GF-20 $480 \mathrm{mg}$ trên 202 bệnh nhân thoái hóa khớp gối giai đoạn II, III. Sau 24 tuần điều trị, ở nhóm can thiệp có $89,2 \%$ bệnh nhân hài lòng cao hơn nhóm chứng $(p<0,01)$, tác dụng không mong muốn chủ yếu đau, cứng khớp sau tiêm, không có tác dụng phụ nghiêm trọng.

\section{KẾT LUẬN}

Liệu pháp tiêm nội khớp acid hyaluronic kết hợp Sorbitol có tác dụng giảm đau nhanh, cải thiện chức năng vận động của khớp gối tốt hơn so với nhóm chứng trong điêu trị thoái hóa khớp gối nguyên phát. Tác dụng không mong muốn ít gặp và không nghiêm trọng.

\section{TÀI LIẸU THAM KHẢO}

1. Zhang $Y$, Jordan JM. Epidemiology of Osteoarthritis. Clin Geriatr Med. 2010;26(3):355-369.

2. Bannuru RR, Natov NS, Obadan IE, et al. Therapeutic trajectory of hyaluronic acid versus corticosteroids in the treatment of knee osteoarthritis: A systematic review and metaanalysis. Arthritis Care Res. 2009;61(12):1704-1711. 3. Rutjes AWS, Jüni P, da Costa BR, et al. Knee: A Systematic Review and Meta-analysis. Ann Intern Med. 2012;157(3).

4. Lavet C, Badoud I, Ammann P. Hyaluronic acid/ sorbitol complex (Synolis VA) improves cartilage material properties. Osteoarthritis and Cartilage. 2017;25:S411-S412.

5. Mongkhon J-M, Thach $\mathbf{M}, \mathbf{S h i} Q$, et al. Sorbitolmodified hyaluronic acid reduces oxidative stress, apoptosis and mediators of inflammation and catabolism in human osteoarthritic chondrocytes. Inflamm Res. 2014;63(8):691-701.

6. Heisel J, Kipshoven C. Safety and Efficacy Findings from a Non-interventional Study of a New Hyaluronic Acid/Sorbitol Formulation (GO-ON@) Matrix) for Intra-articular Injection to Relieve Pain and Disability in Osteoarthritis Patients. Drug Res. 2013;63(09):445-449.

7. Cucurnia I, Pudda A, Madonna V, Berruto M, Zaffagnini S. Patient-reported outcomes of intraarticular hyaluronic acid for osteoarthritis of the knee: a prospective and multicentric case series. Musculoskelet Surg. 2021.

8. Akmal M, Singh A, Anand A, et al. The effects of hyaluronic acid on articular chondrocytes. J Bone Joint Surg Br. 2005;87-B(8):1143-1149.

9. Phạm thị Bích Ngọc. Đánh giá tác dụng điêu trị của liệu pháp tiêm nội khớp bằng acid hyaluronic (Regentflex Bio Plus) trong điều trị thoái hóa khớp gối nguyên phát. Luận văn tốt nghiệp thạc sỹ. Đại học Y Hà Nội 2019. 